\title{
THE INFLUENCE OF CIGARETTE SMOKING ON VARIOUS ASPECTS OF PERIODONTAL HEALTH
}

\author{
Vimal Jacob, Sajith Vellappally, Jindra Šmejkalová
}

\author{
Charles University in Prague, Faculty of Medicine in Hradec Králové, Czech Republic: Department of Hygiene \\ and Preventive Medicine
}

Summary: Tobacco is one of the most important risk factors for oral diseases, including oral cancer, oral mucosal lesions and periodontal diseases. There is substantial evidence suggesting that the risk of oral diseases increases with frequent use of tobacco and that quitting smoking results in reduced risk. In this article, the influence of cigarette smoking on the periodontium will be discussed, giving importance to the effects on immune responses, alveolar bone loss, periodontal pathogens and briefly outlining the negative effects of smoking on wound healing and periodontal treatment procedures.

Key words: Cigarette smoking; Periodontitis; Probing depth; Clinical attachment level

\section{Introduction}

The manifestation and progression of periodontitis, a multifactorial disease with microbial dental plaque as the initiator, is influenced by a variety of determinants and factors. They include subject characteristics, social and behavioral factors, systemic factors, genetic factors, tooth-related factors, microbial composition of dental plaque and other emerging factors (29). Cigarette smoking is a significant risk factor for periodontal disease (33), demonstrated by an increased loss of attachment $(2,16,31)$, development and progression of periodontal inflammation $(13,17)$ and increased gingival recession (28). It has been estimated that smoking accounts for half of all periodontal diseases. There is epidemiological evidence which shows that cigarette smoking is a stronger risk factor for the presence of periodontitis compared to the presence of certain suspected periodontal pathogens (10). The number of cigarettes smoked per day is a major risk-determining factor, doubling the risk for those in the lowest consumption category and increasing it sixfold in the subgroup smoking more than thirty cigarettes per day $(34,38)$. Former smokers have lower rates of periodontitis than present smokers $(1,9,18,23,32,37,38)$. Longitudinal studies indicate that periodontal disease may progress faster in smokers in comparison to non-smokers $(5,38)$. Further research on this topic is necessary to expand the spectrum of knowledge acquired up to this point and to apply it clinically.

\section{Effects on immune response}

Smoking affects various aspects of the host immune response, and the mechanisms by which smoking enhances periodontal degradation are said to be the cumulative effect of elevating putative periodontal pathogens and modulating the host immune response $(10,34,37)$. The composition of bacterial plaque is not altered by smoking but it has been observed that the host's response to bacterial plaque is disturbed (25). Chronic periodontitis is said to be influenced by an interaction of host immune mechanisms and environmental factors (12). Experimental studies on plaque-induced gingivitis in humans suggest that clinical signs of gingival inflammation, namely redness, bleeding and exudation, are not as prominent in smokers as in non-smokers $(24,36)$. Even though the primary etiology of periodontal disease is bacteria, the host response determines a patient's susceptibility to disease. There is enough evidence, indicating that smoking affects the innate and immune host responses $(4,18,22)$. It has been observed that the hemorrhagic responsiveness of the periodontium is lowered in smokers compared to non-smokers (6). The findings of decreased inflammation and reduced gingival crevicular fluid volumes in smokers compared to non-smokers suggest that smoking impairs gingival blood flow. Although smokers actually have significantly higher numbers of neutrophils, the first line of defense against bacterial infection, their function is impaired in peripheral circulation. Neutrophils have shown decreased chemotaxis, phagocytosis, and adherence in smokers. Integrin expression and protease inhibitor production is also affected (18). On the other hand, exposure of unstimulated neutrophils to smoke has been shown to elevate the oxidative burst, which could enhance tissue destruction through direct toxic effect.

Antibody production is another protective host mechanism that is altered by smoking. Smoking generally de- 
creases serum IgG concentrations and decreases IgG2 antiboby production in patients with early onset periodontitis $(15,26)$. Smokers have demonstrated reduced titres of serum IgG to periodontal pathogens like Pervotella Intermedia and Fusobacterium Nucleatum and the level of IgG2 against Actinobacillus Actinomycetemcomitans is lower in smokers compared to non-smokers. The proliferative response of T-cells to antigens is decreased by long term exposure to cigarette smoke $(26,37)$.

\section{Alveolar bone loss}

A higher amount of alveolar bone destruction has been seen in smokers $(7,21,31)$, and the severity of destruction was also found to be greater in smokers compared to nonsmokers (7,8,21). A dose-response effect on alveolar bone has been seen, accelerating the bone loss with higher amount and longer duration of tobacco consumption (3). The bone mineral content among smokers was found to be 10-30 \% lower compared to non-smokers in a longitudinal cohort study, and it was speculated that constituents of tobacco smoke may alter the metabolism of vitamin D or influence hormonal states (12). The periodontal bone height and frequency of diseased sites (probing depth $>4 \mathrm{~mm}$ ) remained stable among non-smokers and smokers who quit before the baseline examination in a long term prospective study, but became worse among subjects who continued to smoke (35). Women who smoke one pack of cigarettes per day throughout their adult lives will have an average deficit in bone density of 5-8 \% by the time they reach menopause. Estrogen metabolism is altered in female smokers and the estrogen deficiency is associated with elevations of IL-1, IL-6 and Tumor Necrosis Factoralpha, which affect both alveolar and systemic bone status (19).

\section{Periodontal pathogens}

Powerful reducing agents such as the carbon monoxide contained in tobacco smoke produce a substantial immediate reduction in redox potential at mucosal surfaces. The powerful physico-chemical reducing activity of carbon monoxide is probably a direct mechanism for promoting the growth of anaerobes at superficial sites rather than simple anaerobiosis (11). Several studies suggest that the types of bacteria in smokers and non-smokers did not vary significantly, but smoking may alter the quality of the flora. A lower oxygen tension in the periodontal pocket of smokers may be favorable for the growth of anaerobic bacteria (19). The oxidation reduction potentials in dental plaque have been shown to be decreased by smoking, possibly encouraging the growth of anaerobic bacteria (15). Plaque formation appears not to be influenced by smoking in several experimental gingival settings; however, there seems to be an altered gingival response to supragingival plaque in smokers. In a steady state situation, in some cross-sectional studies, smokers seem to have more plaque and calculus than non-smokers. It has been conjectured that distinctive personal characteristics of smokers may be responsible for a general trend in neglecting health issues (27).

\section{Effects on wound healing and response to periodontal therapy}

Smokers show a poorer response to periodontal therapy compared to non-smokers $(17,25,30)$. Various studies suggest that smoking adversely effects healing after various forms of periodontal therapy $(14,18)$. In one study, researchers found that ex-smokers were similar to non-smokers in their response to therapy, suggesting that quitting smoking may help in healing (38). Smokers were found to have a lesser reduction in periodontal depth and lesser clinical attachment gain after treatment compared to ex-smokers or nonsmokers (20). In a six year longitudinal study, non-smokers had approximately a $50 \%$ higher rate of improvement in probing depth and clinical attachment levels after periodontal therapy than smokers (19).

Chemical products and toxins in tobacco smoke may delay wound healing by impairing the biologic progression of healing and by inhibiting the basic cellular functions responsible for its initiation. Smoking has a strong negative influence on regenerative therapy, which includes osseous grafting, guided tissue regeneration or a combination of these treatments. The revascularization of bone and soft tissues is impaired by smoking, which could have a strong influence on wound healing, particularly related to regenerative, periodontal and implant therapies. Volatile components of cigarettes namely acrolein and acetaldehyde, may inhibit gingival fibroblast attachment and proliferation. Fibroblasts, which are exposed to nicotine, produce less fibronectin and collagen and more collagenase, and these negative effects on fibroblast functions could influence wound healing and the progression of periodontitis (19).

\section{Conclusion}

For the past 50 years, studies have been conducted at various levels, considering all aspects of tobacco use as an etiological factor for oral diseases, especially periodontitis. It is evident from these studies that cigarette smoking has a negative influence on periodontal health. The ultimate aim of any study conducted in this respect should be to discourage present smokers from continuing and non-smokers or youths from trying to smoke. This review gives a brief picture of the effect of cigarette smoking on different aspects of periodontal health.

\section{Acknowledgement}

Supported by grant IGA MZ ČR NR 8781-3/2006. 


\section{References}

1. Alabandar JM, Streckfus CF, Adesanaya MR, Winn DM. Cigar, pipe and cigarette smoking as risk factors for periodontal disease and tooth loss. J Periodonto 2000; 71:1874-81.

2. Amarasena N, Ekanayaka ANI, Herath L, Miyazaki H. Tobacco use and oral hygiene as risk indicators for periodontitis. Community Dent Oral Epidemiol 2003 31:158-60.

3. Ashri NY, Al-Sulamani A. The effect of different types of smoking habits on periodontal attachment. J Int Academy Periodontol 2003; 5/2:41-46.

4. Barbour SE, Nakashima K, Zhang JB, et al. Tobacco and smoking: Environmental factors that modify the host response (immune system) and have an impact on periodontal health. Crit Rev Oral Biol Med 1997; 8:437-60.

5. Beck JD, Cusmano L, Green-Helms W, Koch GG, Offenbacher S. A 5 year study of attachment loss in community-dwelling older adults: incidence dentistry. J Periodontal Res 1997; 32:506-15.

6. Bergström J, Boström L. Tobacco smoking and periodontal hemorrhagic responsiveness. J Clin Periodontol 2001; 28:680-85.

7. Bergström J, Eliasson S. Cigarette smoking and alveolar bone height in subjects with high standard of oral hygiene. J Clin Periodontol 1987; 14:466-69.

8. Bergström J, Eliasson S, Dock J. A 10-year prospective study of tobacco smoking and periodontal health. J Periodontol 2000; 71:1338-47.

9. Calsina G, Ramón J-M, Echeverrí J-J. Effects of smoking on periodontal tissues. J Clin Periodontol 2002; 29:771-76.

10. Darby IB, Hodge PJ, Riggio MP, Kinane DF. Clinical and microbiological effect of scaling and root planning in smoker and non-smoker chronic aggressive periodontitis patients. J Clin Periodontol 2005; 32/2:200.

11. Eggert FM, McLeod MH, Flowerdew G. Effects of smoking and treatment status on periodontal bacteria: Evidence that smoking influences control of periodontal bacteria at the mucosal surface of the gingival crevice. J Periodontol 2001; 72:1210-20

12. Gelskey SC. Cigarette smoking and periodontitis: Methodology to assess the strength of evidence in support to causal association. Community Dent Oral Epidemiol 1999; 27:16-24

13. Genco RJ. Current view of risk factors for periodontal diseases. J Periodontol 1996; 67:1041-49.

14. Grossi SG, Zambon J, Machtei EE, et al. Effects of smoking and smoking cessation on healing after mechanical periodontal therapy. J Am Dent Assoc 1997; 128:599-07.

15. Haffajee AD, Soucransky SS. Relationship of cigarette smoking to the subgingival microbiota. J Clin Periodontol 2001; 28:377-88.

16. Hyman JJ, Reid BC. Epidemiological risk factors for periodontal loss among adults in the United States. J Clin Periodontol 2003; 30:230-37.

17. James JA, Sayers NM, Drucker DB, Hull PS. Effect of tobacco products on the attachment and growth of periodontal ligament fibroblasts. J Periodontol 1999; 70. $518-25$.
18. Johnson GK, Hill M. Cigarette smoking and the periodontal patient. J Periodontol 2004; 75:196-09.

19. Johnson GK, Slach NA. Impact of tobacco use on periodontal status. J Dent Education 2001; 65:313-21.

20. Kaldahl WB, Johnson GK, Patil KD, Kalkwarf KL. Levels of cigarette consumption and response to periodontal therapy. J Periodontol 1996; 67:675-81.

21. Kervongbundit V, Wikesjo UME. Effect of smoking on periodontal health in molar teeth. J Periodontol 2000; 71:433-37.

22. Kinane DF, Chestnutt IG. Smoking and periodontal disease. Rev Oral Biol Med 2000; 11:356-65.

23. Krejci CB, Bissada NF. Periodontitis-The risk of its development. Academy Gen Dent 1999; 430-36.

24. Lie MA, Timmerman MF, Van der Velden U, Van Der Weijden GA. Evaluation of 2 methods to assess gingival bleeding in smokers and non-smokers in natura and experimental gingivitis. J Clin Periodontol 1998; 25:695-700.

25. Machuca G, Rosales I, Lacalle JR, Machuca C, Bullón P. Effect of cigarette smoking on periodontal status of healthy young adults. J Periodontol 2000; 71:73-78

26. Mooney J, Hodge PJ, Kinane DF. Humoral immune response in early-onset periodontitis: Influence of smoking. J Periodontal Res 2001; 38:351-53.

27. Müller H-P, Stadermann S, Heinecke A. Bleeding on probing in smokers and nonsmokers in a steady state plaque environment. Clin Oral Investigation 2001; 5:177-84

28. Müller H-P, Stadermann S, Heinecke A. Gingival recession in smokers and nonsmokers with minimal periodontal disease. J Clin Periodontol 2002; 29:129-36.

29. Nunn ME. Understanding the etiology of periodontitis: An overview of periodontal risk factors. Periodontology 2000 2003; 32:11-23.

30. Preber H, Bergström J. The effect of non-surgical treatment of periodontal pockets in smokers and non-smokers. Acta Odontol Scand 1986; 44:85-89.

31. Razali M, Palmer RM, Coward P, Wilson RF. A retrospective study of periodontal disease severity in smokers and non-smokers. British Dent Journal 2005; 198:495-98.

32. Spickerman CF, Hujoel PP, DeRouen TR. Bias induced by self-reported smoking on periodontitis-systemic disease associations. J Dent Res 2003; 82/5:345-49.

33. Tanner ACR, Kent RJr, Van Dyke T, Sonis ST, Murray LA. Clinical and other risk indicators for early periodontitis in adults. J Periodontol 2005; 76:573-81.

34. Tomar SL, Asma S. Smoking-attributable periodontitis in the United States: Findings from NHANES III. J Periodontol 2000; 71:743-51.

35. Torrungruang K, Nisapakultorn K, Sutdhibhisal S et al. The effect of cigarette smoking on the severity of periodontal disease among older Thai adults. J Periodontol 2005; 76:566-72.

36. Van der Weijden GA, De Slegte C, Timmerman MF, Van der Velden U. Periodontitis in smokers and non-smokers: intra-oral distribution of pockets. A retrospective study. J Clin Periodontol 2001; 28:955-60.

37. Van Winkelhoff AJ, Bosch-Tijhof CJ, Winkel EG, Van der Reijden WA. Smoking affects the subgingival microflora in periodontitis. J Periodontol 2001; 72:666-71.

38. Winn DM. Tobacco use and oral diseases. J Dent Edu 2001; 65/4:306-10.

Submitted January 2007.

Accepted March 2007.

\section{Corresponding author:}

Dr. Vimal Jacob, BDS, Faculty of Medicine in Hradec Králové, Department of Hygiene and Preventive Medicine, Šimkova 870, 50038 Hradec Králové, Czech Republic, e-mail: vimal.jacob@rediffmail.com 